\title{
The Metabolism of Shikimate in the Rat
}

\author{
By DAVID BREWSTER,* ROBIN S. JONES and DENNIS V. PARKE \\ Department of Biochemistry, University of Surrey, Guildford, Surrey GU2 $5 X H$, U.K.
}

\author{
(Received 28 June 1977)
}

\begin{abstract}
In the rat, shikimate was metabolized and excreted as hippurate, hexahydrohippurate, 3,4,5,6-tetrahydrohippurate, $t$-3,t-4-dihydroxycyclohexane-r-1-carboxylate and $c-3, t-4-$ dihydroxycyclohexane-r-1-carboxylate, conjugates of catechol and $\mathrm{CO}_{2}$. The metabolism was entirely dependent on various initial microbial transformations in the gut, metabolite formation being suppressed in animals pretreated with antibiotics. Shikimate was not metabolized by mammalian tissues, and products of microbial metabolism were excreted either unchanged or after further biotransformation in the animal tissues.
\end{abstract}

Although there is considerable information on the plant biochemistry of shikimate $[(-)-3 \alpha, 4 \alpha, 5 \beta$ trihydroxycyclohex-1-enecarboxylic acid] (Bohm, 1965; Haslam, 1974), little is known of the mammalian metabolism of this ubiquitous plant acid and its many close relatives, such as quinic acid. Claims that shikimate is a mutagen and carcinogen (Evans \& Osman, 1974; Evans, 1976) have added to the need for a further study of the metabolism of this compound, especially since the chemical structure of shikimate does not suggest that it is a potential toxin, even less a carcinogenic compound. This renewed interest in shikimate has prompted both a review (Stavric \& Stoltz, 1976) and initial metabolic studies with rat gastrointestinal micro-organisms (Brewster et al., 1976).

Shikimic acid or quinic acid administered orally to animals gives rise to increased urinary excretion of hippurate (Cotran et al., 1960; Asatoor, 1965; Adamson et al., 1970; Indahl \& Scheline, 1973), which may be inhibited by treatment with antibiotics. The shikimate is metabolized by gastrointestinal microorganisms to cyclohexanecarboxylate, and the latter is aromatized and conjugated with glycine in mammalian tissues (Brewster et al., 1976, 1977a,b,c). This finding is contrary to earlier hypotheses that shikimate is aromatized to benzoate by gastrointestinal micro-organisms. A more detailed investigation of shikimate metabolism in the rat is now presented, together with an assessment of the importance of the involvement of the gastrointestinal microflora in vivo.

\section{Materials and Methods}

\section{Chemicals}

Shikimic acid [m.p. 188-190 C; Sigma (London) Chemical Co., Kingston-upon-Thames, Surrey, U.K.], D-[G- ${ }^{14}$ C]shikimic acid (sp. radioactivity

* Present address: Department of Drug Metabolism, Pharmaceutical Division, Reckitt and Colman, Dansom Lane, Hull HU8 7DS, U.K.
$20.7 \mathrm{mCi} / \mathrm{mmol}$; New England Nuclear Corp., Dreieichenhain, W. Germany), and D-[2,3,4,5(n)- $\left.{ }^{14} \mathrm{C}\right]-$ shikimic acid (sp. radioactivity $64 \mathrm{mCi} / \mathrm{mmol}$; The Radiochemical Centre, Amersham, Bucks., U.K.) were used. All samples of shikimic acid, labelled or otherwise, were shown to contain no detectable impurities by co-chromatography on manufacturers' recommended t.l.c. systems. Neomycin, tetracycline and hippuric acid (Sigma), and chlorotrimethylsilane, hexamethyldisilazane and NO-bis(trimethylsilyl)acetamide (Pierce Chemical Co., Rockford, IL, U.S.A.), were also purchased. Hexahydrohippuric acid and 3,4,5,6-tetrahydrohippuric acid were obtained in the urine as metabolites of cyclohexanecarboxylic acid administered intraperitoneally to rats; the structures of the purified compounds were authenticated by electron-impact mass spectrometry and proton magnetic resonance (Brewster et al., 1977b).

\section{Animals}

Male Wistar albino rats (220-250g) were used. Where necessary, the gastrointestinal microflora were suppressed by administration of a solution of neomycin $(40 \mathrm{mg})$ and tetracycline $(20 \mathrm{mg})$ in $0.25 \mathrm{ml}$ of water (twice daily for 4 days, and once on the fifth day $1-2 \mathrm{~h}$ before the experiment).

\section{Studies in vivo}

Animals were maintained in glass metabolism cages (Jencons Scientific, Hemel Hempstead, Herts., U.K.) and urine and faeces were collected separately for $24 \mathrm{~h} ; \mathrm{CO}_{2}$ was collected by drawing through a series of ethanolamine/2-ethoxyethanol $(1: 4, \mathrm{v} / \mathrm{v})$ solvent traps at a rate of $200 \mathrm{~cm}^{3} / \mathrm{min}$. Each animal received $100 \mathrm{mg}(6-15 \mu \mathrm{Ci})$ of $\left[{ }^{14} \mathrm{C}\right]$ shikimate $/ \mathrm{kg}$ body wt. in $0.5 \mathrm{ml}$ of water as vehicle.

To permit direct collection of urine and bile, ureters and bile ducts were cannulated (Brewster et al., 1977b). Anaesthetized animals received 
$\left[{ }^{14} \mathrm{C}\right]$ shikimate $(50-100 \mathrm{mg} / \mathrm{kg}$ body wt., $4 \mu \mathrm{Ci})$ in $0.5 \mathrm{ml}$ of water by intraperitoneal injection. Urine and bile were collected for up to $7 \mathrm{~h}$.

\section{Studies in vitro}

Isolated-liver-perfusion experiments were performed by the method of Brewster et al. (1977c). Rats were anaesthetized with sodium pentobarbital (Nembutal, $60 \mathrm{mg} / \mathrm{kg}$ body wt.; Abbott Laboratories, Queenborough, Kent, U.K.), and the bile duct and hepatic portal vein of each rat cannulated with pp25 and pp60 polypropylene tubing (Portex, Hythe, Kent, U.K.) respectively. An infusion of the liver in situ $(10 \mathrm{ml} / \mathrm{min})$ with $50 \mathrm{ml}$ of tissue-culture Medium 199 without Phenol Red (Difco Laboratories, Detroit, MI, U.S.A.) containing $1.25 \mathrm{~g}$ of bovine serum albumin (fraction V; Sigma Chemical Co., St. Louis, MO, U.S.A.), 250i.u. of heparin (BDH Chemicals, Poole, Dorset, U.K.) and $40 \mathrm{mg}$ of gentamycin (Flow Laboratories, Irvine, Ayrshire, Scotland, U.K.) was performed during hepatectomy, after which the liver was connected into the recirculating perfusion system. The liver was then perfused for $5 \mathrm{~h}$ at a rate of $1 \mathrm{ml} / \mathrm{min}$ per $\mathrm{g}$ of liver under $30 \mathrm{~cm}$ hydrostatic pressure with an oxygenated $\left(\mathrm{O}_{2} / \mathrm{CO}_{2}, 19: 1\right)$ bicarbonate-buffered medium comprising $65 \mathrm{ml}$ of tissueculture Medium 199 without Phenol Red, 1.6g of bovine serum albumin, 325 i.u. of heparin, $50 \mathrm{mg}$ of gentamycin, $12.5 \mathrm{mg}$ of $\left[{ }^{14} \mathrm{C}\right]$ shikimate $(5-6 \mu \mathrm{Ci})$ and goat erythrocytes, washed three times with $0.9 \%$ (w/v) $\mathrm{NaCl}(35 \%$ haematocrit). Samples of perfusate and bile were collected at intervals throughout.

Incubation of test compounds with samples of rat caecal or faecal micro-organisms was carried out essentially as described by Scheline (1966). The incubation medium contained $0.55 \%(\mathrm{w} / \mathrm{v})$ each of $\mathrm{D}$-glucose, proteose peptone (Difco Laboratories) and yeast extract (Difco Laboratories) in $0.1 \mathrm{M}$ sodium phosphate buffer, $\mathrm{pH}$ 7.4. Anaerobic incubation in $10 \mathrm{ml}$ at $37^{\circ} \mathrm{C}$ for $48 \mathrm{~h}$ was begun after addition of $0.5 \mathrm{ml}$ of a $10 \%(\mathrm{w} / \mathrm{v})$ suspension of caecal contents or homogenized fresh rat faeces, both prepared in the phosphate buffer. Acidified incubation mixtures (pH1) were extracted with $3 \times 10 \mathrm{ml}$ of either ethyl acetate or diethyl ether.

\section{Measurement of radioactivity}

Radioactivity was determined in an LKB 1210 or a Packard 3320 liquid-scintillation counter. Three scintillation systems were used: (1) $0.55 \% 2,5-$ diphenyloxazole in Synperonic NXP (I.C.I., Billingham, Cleveland, U.K.)/toluene $(1: 2, \mathrm{v} / \mathrm{v})$ (Wood et al., 1975); (2) $0.55 \%$ 2,5-diphenyloxazole in toluene containing $4 \%$ thixotrophic gel (Packard, La Grange, IL, U.S.A.); (3) Insta-Gel (Packard). Counting effi- ciencies were obtained by internal standardization with $\left[{ }^{14} \mathrm{C}\right]$ hexadecane. Fluids and excreta were treated as follows. Samples $(500 \mu \mathrm{l})$ of aq. $5 \%(\mathrm{w} / \mathrm{v})$ homogenates of $24 \mathrm{~h}$ faecal samples were dispensed into glass scintillation vials and heated with $3 \mathrm{ml}$ of Hyamine hydroxide (Packard) at $55-60^{\circ} \mathrm{C}$ for $5 \mathrm{~h}$. After cooling, $30 \% \mathrm{H}_{2} \mathrm{O}_{2}(250 \mu \mathrm{l})$ was added and the solution decolorized overnight. Digests were neutralized with $12 \mathrm{M}-\mathrm{HCl}(250 \mu \mathrm{l})$ and suspended in scintillant $3(10 \mathrm{ml})$. Urine samples were diluted to 50 or $100 \mathrm{ml}$ and samples $(100 \mu \mathrm{l})$ suspended in scintillant $1(4 \mathrm{ml})$. For ${ }^{14} \mathrm{CO}_{2}$, methanol $(4 \mathrm{ml})$ was added to $5 \mathrm{ml}$ of trapping medium and the solution counted for radioactivity in scintillant $2(10 \mathrm{ml})$. Bile $(50 \mu \mathrm{l})$ was counted directly for radioactivity in scintillant $1(4 \mathrm{ml})$, and samples $(50 \mu \mathrm{l})$ of cell-free perfusate, prepared as described previously (Brewster et al., 1977c), were suspended in scintillant $1(10 \mathrm{ml})$.

\section{Solvent extraction_of samples}

Two methods of extraction were used for the urine. (a) For examination of metabolites formed via the microbial-dependent cyclohexanecarboxylate pathway, $5 \mathrm{ml}$ of diluted urine $(1: 1, \mathrm{v} / \mathrm{v})$ was acidified to pH1 with $5 \mathrm{M}-\mathrm{HCl}$ and extracted with $5 \times 6 \mathrm{ml}$ portions of ethyl acetate. The extracts were evaporated to dryness and dissolved in methanol $(200 \mu \mathrm{l})$ for analysis by t.l.c. on system A. (b) For analysis of whole urine, $5 \mathrm{ml}$ of diluted urine $(1: 1$, $\mathrm{v} / \mathrm{v}$ ) was freeze-dried, the residue suspended in methanol $(10 \mathrm{ml})$ and transferred to a chromatography column $(15 \mathrm{~cm} \times 1 \mathrm{~cm}$ internal diam. $)$ containing $1 \mathrm{~g}$ of silica gel (Kieselgel 60; E. Merck, Darmstadt, W. Germany). The clear methanolic eluate was collected and the silica further eluted with methanol $(10 \mathrm{ml})$. Extracts were combined, evaporated and dissolved in methanol $(300 \mu \mathrm{l})$ for examination by t.l.c.

Samples $(10 \mathrm{ml})$ of aq. $5 \%(\mathrm{w} / \mathrm{v})$ homogenates of $24 \mathrm{~h}$ faecal samples were freeze-dried and suspended in methanol $(10 \mathrm{ml})$. Suspensions were transferred to silica-gel columns $(15 \mathrm{~cm} \times 1 \mathrm{~cm}$ internal diam.), the eluates collected and the silica was further eluted with methanol $(20 \mathrm{ml})$. Methanolic extracts were combined, decolorized with activated charcoal $(100 \mathrm{mg})$ and, after filtration, were evaporated to dryness and dissolved in methanol $(200 \mu l)$ for analysis by t.l.c.

Whole perfusate was centrifuged at $2000 \mathrm{~g}$ for $2 \mathrm{~min}$ and samples $(5 \mathrm{ml})$ of the supernatant were freezedried. Residues were then ground with silica gel (1 g), eluted with methanol $(40 \mathrm{ml})$, evaporated to dryness and dissolved in aq. $50 \%(\mathrm{v} / \mathrm{v})$ methanol for analysis by t.l.c. Before concentration to small volume, samples of all extracts were counted for radioactivity and the extraction efficiency of each procedure was determined. 


\section{Chromatography}

T.l.c. was carried out on $0.25 \mathrm{~mm}$-thick plates of silica gel GF $_{254}$ (Schleicher and Schull, distributed by Anderman and Co., East Molesey, Surrey, U.K.) and preparative-layer chromatography on silica gel $60 \mathrm{~F}_{254}$ plates of $2 \mathrm{~mm}$ thickness (E. Merck, Darmstadt, W. Germany). The following solvent systems were used: A, acetone/light petroleum (b.p. $\left.40-60^{\circ} \mathrm{C}\right) /$ acetic acid $(20: 40: 1$, by vol.); B, propan-1-ol/conc. $\mathrm{NH}_{3}$ (sp.gr. 0.88) $(7: 3, \mathrm{v} / \mathrm{v})$; C, butan-1-ol/acetic acid/water (4:1:1, by vol.); $\mathrm{D}$, toluene/ethyl acetate/methanol/conc. $\mathrm{NH}_{3}$ (sp.gr. $0.88)(1: 5: 2: 1$, by vol.); E, ethyl acetate/methanol/ conc. $\mathrm{NH}_{3}$ (sp.gr. 0.88) (3:2:1, by vol.); F, methanol/ chloroform $(1: 6, v / v)$. Acidic compounds were detected by spraying the dried plates with $0.04 \%$ Bromocresol Green in ethanol (Lugg \& Overall, 1948). Shikimate and other 1,2-diols were detected by spraying chromatograms lightly with $0.01 \mathrm{M}$ sodium metaperiodate, followed (after $5 \mathrm{~min}$ ) by a solution of $0.9 \%(\mathrm{w} / \mathrm{v})$ soluble starch, $0.8 \%(\mathrm{w} / \mathrm{v})$ $\mathrm{KI}$ and $0.9 \%(\mathrm{w} / \mathrm{v})$ boric acid in saturated sodium tetraborate (Metzenberg \& Mitchell, 1954). Compounds oxidized by periodate gave white spots against a blue background.

Radioautographs of thin-layer chromatograms were produced on medical X-ray films (BB54; $18 \mathrm{~cm} \times 24 \mathrm{~cm}$; Kodak, Hemel Hempstead, Herts., U.K.) by contact exposure for suitable periods of time (1-14 days).

\section{Mass spectrometry}

Electron-impact mass spectra were recorded on an AEI MS12 mass spectrometer by using direct sample insertion. Spectra were recorded at $70 \mathrm{eV}$ with a source temperature of $200-250^{\circ} \mathrm{C}$.

For identification of metabolites 1-3, ethyl acetate extracts of urine were chromatographed with solvent system $\mathrm{A}$, the metabolites located by radioautography, then removed, eluted with methanol and chromatographed individually in solvent system B. The required radioactive zones were prepared for analysis by the technique of Rix et al. (1969).

Metabolite 4 was purified from the decolorized methanolic extracts of freeze-dried faeces (see above) from three normal rats. The extracts were subjected to preparative-layer chromatography in solvent system B. The metabolite was located, eluted, acidified with $\mathrm{HCl}(5 \mu \mathrm{l})$ and subjected to t.l.c. in solvent systems $C, D$ and $E$, applied sequentially. The purified material was acidified with $\mathrm{HCl}(5 \mu \mathrm{l})$ in water $(1 \mathrm{ml})$ and freeze-dried.

A methanolic solution $(5 \mathrm{ml})$ of metabolite 4 (a carboxylic acid) was esterified by addition of an excess of ethereal diazomethane and the resulting esters were purified by t.l.c. in solvent system F.
Suspected cis-1,2-diols (metabolite 4a) were esterified and purified as above, the diol esters being removed from the t.l.c. plates and eluted with methanol. After evaporation of the methanol under $\mathrm{N}_{2}$, residues $(50-200 \mu \mathrm{g})$ were left for $24 \mathrm{~h}$ in acetone $(300 \mu \mathrm{l})$ containing catalytic amounts $(10-100 \mu \mathrm{g})$ of $p$ toluenesulphonic acid. The acetone solution was subjected to t.l.c. in solvent system $F$ and acetonide derivatives were removed and eluted with acetone. Samples were then prepared for direct-insertion mass spectrometry as described above.

Metabolite 5, believed to be unchanged shikimate, was isolated from the methanolic extract of freezedried urine (see above). This was chromatographed as $5 \mathrm{~cm}$ bands in solvent system $B$. The required radioactive zones were located, eluted and acidified as described above and chromatographed in solvent system C. Finally, the radioactive zones were removed and eluted with methanol into small conical glass vials for derivative formation with hexamethyldisilazane $(20 \mu \mathrm{l})$ and chlorotrimethylsilane $(10 \mu \mathrm{l})$ in acetone $(300 \mu \mathrm{l})$. After $10 \mathrm{~min}$ the solution was separated from precipitated $\mathrm{NH}_{4} \mathrm{Cl}$ and the derivative [probably tetrakis(trimethylsilyl)shikimate] prepared for mass spectrometry.

\section{Quantitative determination of metabolites}

Hippurate (metabolite 3) was determined by reverse isotope dilution of ethyl acetate extracts of urine, samples being recrystallized from methanol to constant specific radioactivity.

For catechol (metabolite 6), diluted urine $(5 \mathrm{ml})$ was heated with an equal volume of $4 \mathrm{M}-\mathrm{HCl}$ at $90-95^{\circ} \mathrm{C}$ for $30 \mathrm{~min}$, cooled and extracted with $3 \times 10 \mathrm{ml}$ portions of ethyl acetate. The combined extracts were evaporated to dryness under reduced pressure, dissolved in methanol and total catechol determined by reverse isotope dilution.

Shikimate (metabolite 5) and metabolites 1,2 and 4 were determined by quantitative radioassay after separation on t.l.c. Radioactive metabolites, located by radioautography, were removed and counted for radioactivity in scintillant $2(4 \mathrm{ml})$.

\section{Results}

After administration of $\left[{ }^{14} \mathrm{C}\right]$ shikimate to rats, over $95 \%$ of the radioactivity was excreted in the urine, faeces and expired air within $24 \mathrm{~h}$ (Table 1). After intraperitoneal administration all of the dose was excreted in the urine, whereas after oral dosing approximately equal amounts were recovered in urine and faeces. In animals pretreated with a combination of neomycin and tetracycline, the urinary excretion of radioactivity after oral administration was greatly decreased. 
Table 1. Excretion of ${ }^{14} C$-labelled metabolites after administration of $\left[{ }^{14} C\right]$ shikimate to rats

In all experiments, shikimate was administered at a dosage of $100 \mathrm{mg} / \mathrm{kg}$ body wt. Numbers of individual animal experiments are given in parentheses.

Percentage of dose excreted over $24 \mathrm{~h}$

\begin{tabular}{llcccc}
\cline { 3 - 5 } \multicolumn{1}{c}{ Route } & Treatment of rats & Faeces & Urine & Expired air & Total recovery \\
Oral & None (7) & $45-63$ & $40-57$ & $4-7$ & $95-97$ \\
Oral & Antibiotic-treated (3) & $75-81$ & $12-16$ & $\dagger$ & $93-96$ \\
Intraperitoneal & None (3) & $<1$ & $97-100$ & $<0.8$ & $98-100$
\end{tabular}

$\dagger$ Not determined.

\section{Metabolism in vivo}

Intraperitoneal administration of $\left[{ }^{14} \mathrm{C}\right]$ shikimate to anaesthetized rats, cannulated for direct collection of urine and bile, resulted in almost complete $(97-100 \%)$ elimination of the dose in the urine (see Table 1). A very small degree of biliary excretion was observed $(<0.8 \%$ after $7 \mathrm{~h})$, but this was not further investigated. Methanol extraction of freezedried urine removed over $98 \%$ of the radioactivity, and t.l.c. of these extracts revealed one component only, which co-chromatographed with authentic shikimate. This was confirmed as shikimate by mass spectrometry of the tetrakis(trimethylsilyl) derivative, the spectrum $\left(\mathrm{M}^{+}, \mathrm{m} / \mathrm{e} 462\right)$ being identical with that of authentic tetrakis(trimethylsilyl)shikimate.

Oral administration of $\left[{ }^{14} \mathrm{C}\right]$ shikimate to normal rats gave a more complex metabolic profile with $40-57 \%$ of the radioactive dose eliminated in the urine, $45-63 \%$ in the faeces, and $4-7 \%$ as $\mathrm{CO}_{2}$. Ethyl acetate extracts of the urine contained $34-40 \%$ of the dose, which was present as metabolites 1-3 (Fig. 1). These metabolites were identified by t.l.c. and mass spectrometry as being (1) hexahydrohippurate $\left(M^{+}, m / e\right.$ 185), (2) 3,4,5,6-tetrahydrohippurate $\left(M^{+}, m / e\right.$ 183) and (3) hippurate $\left(M^{+}, m / e\right.$ 179) (Table 2), and were present in amounts equivalent to $0.8-1.3 \%, 2.0-3.5 \%$ and (Table 3 ) $21-30 \%$ of the dose respectively. Analysis of whole urine revealed the presence of three further metabolites $(4,5$ and 6$)$. These were shikimate (5), confirmed by mass spectrometry of the tetrakis(trimethylsilyl) derivative $\left(M^{+}\right.$, $m / e$ 462) (Table 2), catechol (6), confirmed by reverse isotope dilution of hydrolysed urine and t.l.c., and a hitherto unknown metabolite (4; see below). These metabolites were present in amounts equivalent to $8-12 \%, 0.6-1.9 \%$ and $2.3-3.2 \%$ of the radioactive dose respectively. The radioactivity present in the faeces (45-63\% of the dose) of these animals was identified as unchanged shikimate $(7.1-14.0 \%$ of the dose) and metabolite $4(27.4-35.0 \%$ of the dose), together with small amounts (5-9\% of the dose) of at least two further unknown metabolites.

Pretreatment of animals with antibiotics affected the metabolic profile greatly, with most of the radioactivity ( $75-81 \%$ of the dose) now being excreted in the faeces. Much of this was in the form of unchanged shikimate $(58-71 \%$ of the dose), the remainder being metabolite 4 ( $2-5 \%$ of the dose). Urinary excretion was decreased to $12-16 \%$ of the dose, comprising unchanged shikimate $(8-12 \%$ of the dose), hippurate (1-2\% of the dose) and metabolite 4 $(0.2-0.5 \%$ of the dose). Catechol, tetrahydrohippurate and hexahydrohippurate were barely detectable.

\section{Metabolism in vitro}

The perfusion of isolated rat livers with shikimate resulted in no detectable uptake of radioactivity from the perfusate. Trace amounts $(<0.8 \%$ of the dose over $5 \mathrm{~h}$ ) were excreted in bile, but these were not further investigated. Methanol extraction of the freeze-dried erythrocyte-free perfusate recovered $95-98 \%$ of the administered dose. T.1.c. of this extract revealed a single radioactive component, which co-chromatographed with authentic shikimate, and gave a tetrakis(trimethylsilyl) derivative with a mass spectrum consistent with the structure of tetrakis(trimethylsilyl)shikimate.

Anaerobic incubation of $\left[{ }^{14} \mathrm{C}\right]$ shikimate with rat caecal and faecal micro-organisms in vitro gave rise to the production of cyclohexanecarboxylate (see also Brewster et al., 1976), reverse-isotope-dilution analysis showing a $95-100 \%$ conversion. No other products were observed. Incubation of metabolites $4 a$ and $4 b$, purified from rat faeces (see below), did not give rise to cyclohexanecarboxylate and they were recovered unchanged.

\section{Identification of metabolite 4}

Metabolite 4 was a major metabolite in faeces and a minor one in urine after oral administration of shikimate to normal rats. Purification of the faeces from three such animals yielded $3 \mathrm{mg}$ of the compound. T.l.c. in solvent system B showed it to be acidic (by its reaction with ethanolic Bromocresol Green), fully saturated (by its failure to quench the fluorescence of u.v. light at $254 \mathrm{~nm}$ ) and 
to contain a 1,2-diol group (by its reaction with the periodate/iodide spray reagent). After esterification, t.l.c. in solvent system $F$ revealed two discrete radioactive components (metabolites $4 \mathrm{a}$ and $4 \mathrm{~b}$ ), with $\boldsymbol{R}_{F}$ values of 0.52 and 0.47 respectively, the electronimpact mass spectra of which were almost identical
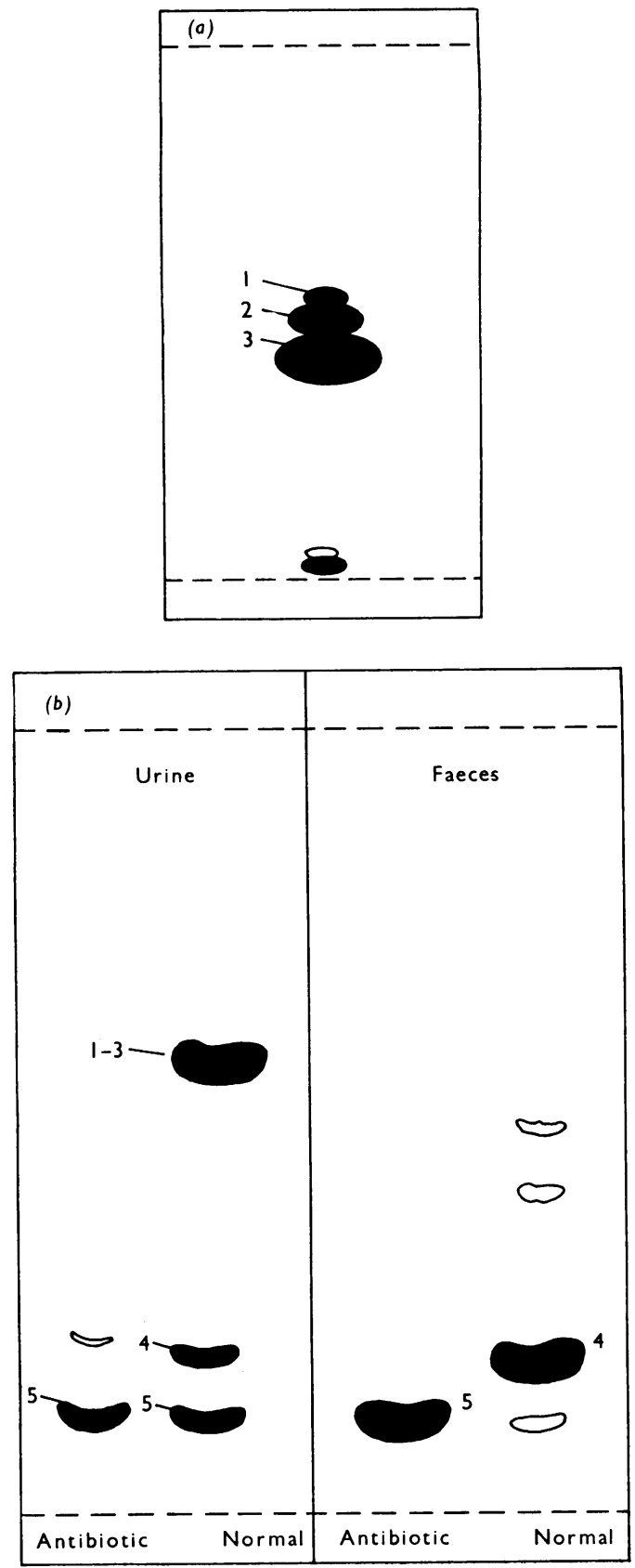

Vol. 170 and consistent with methyl dihydroxycyclohexanecarboxylate. Parent ions were not observed ions of highest mass $(m / e 156)$ corresponding to $\left(\mathrm{M}-\mathrm{H}_{2} \mathrm{O}\right)^{+}$, an effect also observed with shikimate (Table 2).

The specificity of acid-catalysed condensations of cis-1,2-diols with acetone to form acetonide derivatives was used to characterize metabolites $4 \mathrm{a}$ and $4 \mathrm{~b}$ further. Thus the methyl ester of metabolite $4 \mathrm{a}$ was converted into a compound with diminished chromatographic polarity and with a mass spectrum consistent with the structure of the acetonide derivative of methyl cis-3,4-dihydroxycyclohexanecarboxylate (Table 2). Metabolite $4 \mathrm{a}$ is therefore identified as cis-3, 4-dihydroxycyclohexanecarboxylate. The highest $m / e$ observed in the acetonide spectrum was 199 $\left[(M-15)^{+}\right]$, representing the direct loss of a methyl radical. Parent ions are not observed in spectra of acetonides, and molecular weights are normally calculated from the peak attributed to $M-15$ (Budzikiewicz et al., 1967) The methyl ester of metabolite $4 \mathrm{~b}$ did not form an acetonide derivative under the same conditions and was recovered unchanged. Hence metabolite $4 \mathrm{~b}$ was identified as trans-3,4-dihydroxycyclohexanecarboxylate.

\section{Discussion}

Previous studies have shown that in mammals shikimate and quinate are metabolized and excreted in the urine as hippurate (Cotran et al., 1960; Asatoor, 1965; Adamson et al., 1970; Indahl \& Scheline, 1973) and conjugates of catechol (Booth et al., 1960; Indahl \& Scheline, 1973; Brewster et al., 1976). It has long been known that the gastrointestinal microflora play an important role in this metabolism and benzoate was thought to be the crucial microbial intermediate. However, the present study has shown that the mammalian metabolism of shikimate is far more complex than had been expected.

After oral administration of $\left[{ }^{14} \mathrm{C}\right]$ shikimate to rats, hippurate was identified as the major metabolite in the urine, together with small amounts of cis-3,4dihydroxycyclohexanecarboxylate, trans - 3,4-dihy droxycyclohexanecarboxylate, conjugated catechol,

Fig. 1. Thin-layer chromatography of extracts of urine and faeces from rats given oral $\left[{ }^{14} \mathrm{C}\right]$ shikimate

(a) Ethyl acetate extracts of urine in solvent system A.

(b) Methanol extracts of freeze-dried urine and faeces in solvent system $B$ for antibiotic-treated and normal rats. X-ray film was exposed by direct contact with developed chromatograms and then photographed by contact printing. Key to metabolites: 1, hexahydrohippurate; 2, 3,4,5,6-tetrahydrohippurate; 3, hippurate; 4, 3,4-dihydroxycyclohexanecarboxylates; 5 , unchanged shikimate. The upper horizontal broken lines represent the solvent front and the lower lines indicate the origin. 
Table 2. Electron-impact mass spectra of shikimate and its metabolites in the rat

Values represent the six more important ions observed in the spectra $(70 \mathrm{eV})$ and are arranged in order of decreasing relative abundances (percentages, given in parentheses). ${ }^{*}, M^{+} ; \dagger,(M-18)^{+} ; \ddagger,(M-15)^{+}$; ions of highest $m / e$ in the spectra.

\begin{tabular}{|c|c|c|c|c|c|c|c|}
\hline Metabolite & Mol.wt. & & & & & & \\
\hline Shikimate & 174 & $60(100)$ & $97(65)$ & $69(42)$ & $41(40)$ & $138(38)$ & $156 \dagger(20)$ \\
\hline Tetrakis(trimethylsilyl)shikimate & 462 & $73(100)$ & $204(97)$ & $147(24)$ & $205(22)$ & $75(20)$ & $462 *(6)$ \\
\hline Hexahydrohippurate & 185 & $55(100)$ & $83(71)$ & $41(59)$ & $130(20)$ & $111(15)$ & $185^{*}(13)$ \\
\hline 3,4,5,6-Tetrahydrohippurate & 183 & $109(100)$ & $108(95)$ & $81(79)$ & $79(41)$ & $57(27)$ & $183 *(10)$ \\
\hline Hippurate & 179 & $105(100)$ & 77 (89) & $135(30)$ & $106(25)$ & $134(16)$ & $179 *(2)$ \\
\hline $\begin{array}{l}\text { Methyl cis-3,4-dihydroxycyclo- } \\
\text { hexanecarboxylate }\end{array}$ & 174 & $97(100)$ & $41(82)$ & $87(68)$ & $55(61)$ & $44(50)$ & $156 \dagger($ \\
\hline $\begin{array}{l}\text { Methyl trans-3,4-dihydroxycyclo- } \\
\text { hexanecarboxylate }\end{array}$ & 174 & $44(100)$ & $87(61)$ & $97(55)$ & $41(54)$ & $55(50)$ & $156 \dagger$ \\
\hline $\begin{array}{l}\text { Methyl cis-3,4-dihydroxycyclo- } \\
\text { hexanecarboxylic acid acetonide }\end{array}$ & 214 & $43(100)$ & $41(85)$ & $57(59)$ & $45(51)$ & $199 \ddagger(47)$ & $55 \quad(46)$ \\
\hline
\end{tabular}

Table 3. Amounts of shikimate and metabolites excreted by normal and antibiotic-treated rats Values represent means \pm S.E.M. of three- or six-animal experiments after oral dosing with $\left[{ }^{14} \mathrm{C}\right]$ shikimate ( $100 \mathrm{mg} / \mathrm{kg}$ body wt. , 4-10 $\mu \mathrm{Ci})$.

\begin{tabular}{|c|c|c|c|}
\hline \multirow[b]{2}{*}{ Metabolite } & \multirow{2}{*}{$\begin{array}{l}\text { Route of } \\
\text { excretion }\end{array}$} & \multicolumn{2}{|c|}{ Percentage of dose recovered } \\
\hline & & Normal rats & Antibiotic-treated rats \\
\hline Shikimate & Faeces & $8.8 \pm 2.6(3)$ & $64 \pm 4$ \\
\hline Hippurate & Urine & $27.1 \pm 1.5(6)$ & $1.5 \pm 0.3$ \\
\hline Catechol & Urine & $1.1 \pm 0.2(6)$ & $<0.08 *(3)$ \\
\hline Dihydroxycyclohexanecarboxylates & Urine & $2.6 \pm 0.3(3)$ & $0.35 \pm 0.13(3)$ \\
\hline Dihydroxycyclohexanecarboxylates & Faeces & $31.4 \pm 1.5(3)$ & $3.7 \pm 0.2$ \\
\hline
\end{tabular}

hexahydrohippurate, 3,4,5,6-tetrahydrohippurate and unchanged shikimate. The last-named metabolite was also present in the faeces, but the two 3,4-dihydroxycyclohexanecarboxylates together represented about $60 \%$ of the radioactivity in this fraction. In contrast, when administered by intraperitoneal injection, all the shikimate was excreted unchanged in the urine within $7 \mathrm{~h}$. The acid also remained unchanged in the perfusate after recirculation through isolated liver preparations for $5 \mathrm{~h}$.

When incubated anaerobically with gastrointestinal micro-organisms, shikimate was converted quantitatively into cyclohexanecarboxylate, a compound known to be metabolized by rat liver to hippurate, 3,4,5,6-tetrahydrohippurate and hexahydrohippurate (Brewster et al., 1977c). The 3,4dihydroxycyclohexanecarboxylates and catechol were not detected during these incubations with microflora, nor were they further metabolized to cyclohexanecarboxylate when they were incubated under similar conditions. However, the microbial origin of these diols was confirmed by the fact that oral administration of antibiotics to rats dramatically decreased their production, the radioactive dose of shikimate then being excreted in the faeces almost entirely unchanged.

These results suggest that shikimate (I) is metabolized by gut micro-organisms to cyclohexanecarboxylate (III) and cis-3,4- and trans-3,4-dihydroxycyclohexanecarboxylates (VII and VIII) via different pathways (Scheme 1). The cyclohexanecarboxylate is then absorbed from the intestine, metabolized in the liver and excreted in the urine as hexahydrohippurate (VI), 3,4,5,6-tetrahydrohippurate (V) and hippurate (IV), as shown in previous studies (Brewster et al., 1977b,c). Benzoyl and cyclohexylcarbonyl $\beta$-D-glucuronides were not detected, but this is consistent with a slow release of cyclohexanecarboxylate in the gut (Brewster et al., 1977b). Most of the 3,4-dihydroxycyclohexanecarboxylate was not absorbed and was excreted in the faeces unchanged. However, small amounts did appear in the urine, and it is feasible that aromatization of these compounds in rat tissues could explain the formation of catechol. Protocatechuate (XI) produced in this way would be expected to furnish catechol (XII) on biliary excretion into the gut, since gastrointestinal micro-organisms are known to be capable of this 


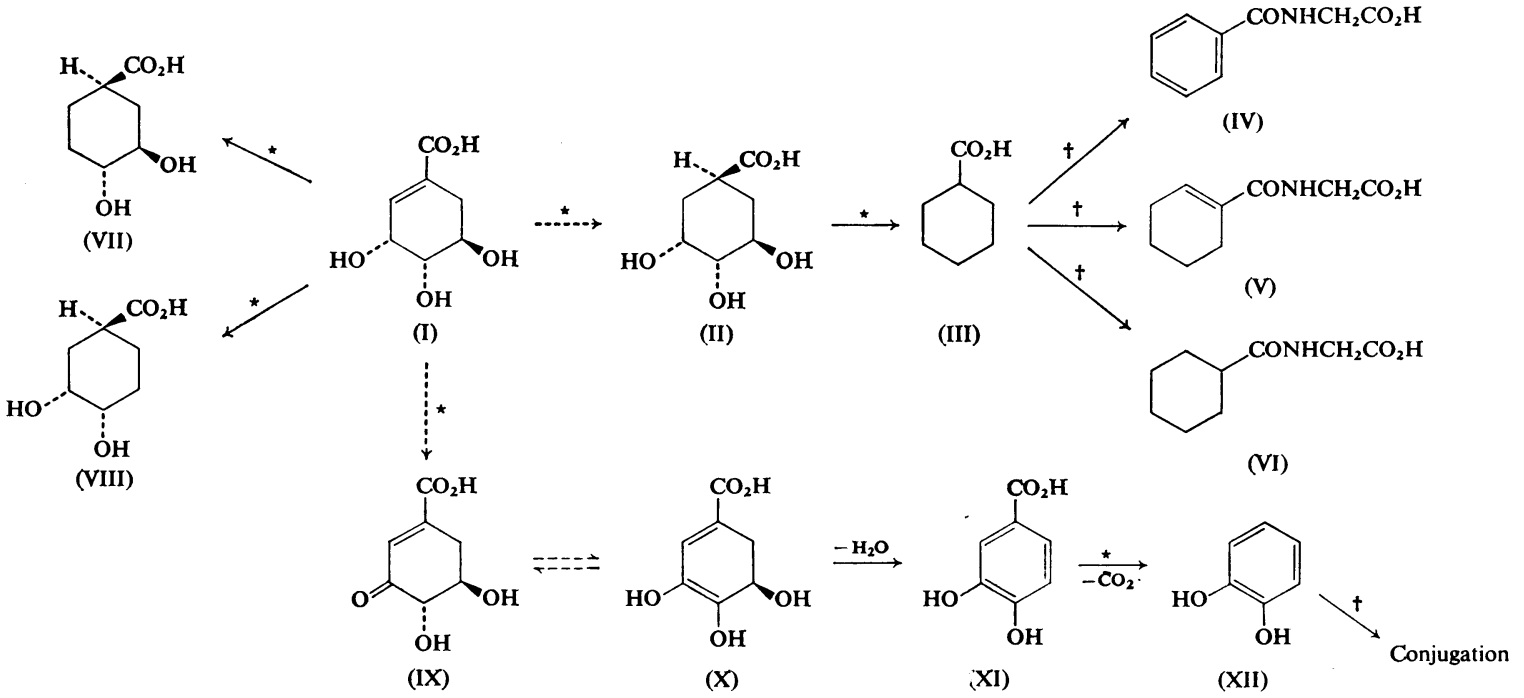

Scheme 1. Metabolism of shikimate in the rat

Key to metabolites: (I) (-)-shikimate; (II) dihydroshikimate; (III) cyclohexanecarboxylate; (IV) hippurate; (V) 3,4,5,6-tetrahydrohippurate; (VI) hexahydrohippurate; (VII) $c$-3,t-4-dihydroxycyclohexane-r-1-carboxylate; (VIII) $t$-3,t-4-dihydroxycyclohexane-r-1-carboxylate; (IX) $t$-4,5-dihydroxy-3-oxocyclohex-1-enecarboxylate; (X) 3,4,5trihydroxycyclohexa-1,3-dienecarboxylate; (XI) protocatechuate; (XII) catechol. The configurations at C-1 in (II), (VII) and (VIII) are inferred, not confirmed. Broken arrows represent likely pathways only and continuous arrows are established pathways. *Metabolism by intestinal micro-organisms. †Metabolism by mammalian tissues.

decarboxylation process (Scheline, 1966). Alternatively, microbial aromatization of shikimate to protocatechuate followed by decarboxylation may account for the formation of catechol (Indahl \& Scheline, 1973) and has been demonstrated for shikimate and quinate with Lactobacillus plantarum anaerobically (Whiting \& Coggins, 1971). This could occur via enolization of $3 \mathbf{H}$-shikimate derivative (IX) to 3,4,5-trihydroxycyclohexa-1,3-diene-1-carboxylate (X) (see Scheme 1). Whiting \& Coggins (1974) have also shown that an NAD-dependent hydro-aromatic dehydrogenase isolated from Lactobacillus plantarum is capable of reducing (-)-quinate and (-)-shikimate to (-)-t-3,t-4-dihydroxycyclohexane-r-1-carboxylate [i.e. with the same configuration as (-)-quinate]. [See IUPAC Rules (1970).] In addition, this reductive degradation was accompanied by an oxidative pathway leading to the formation of catechol. Whatever the initial mechanism, microbial decarboxylation could explain the formation of ${ }^{14} \mathrm{CO}_{2}$ after shikimate administration, and Dacre \& Williams (1968) have shown that $\left[\right.$ carboxy- $\left.{ }^{14} \mathrm{C}\right]$ protocatechuate is metabolized to ${ }^{14} \mathrm{CO}_{2}$ when incubated with rat intestinal contents.

Since shikimate occurs widely in plants and fruits, all the metabolites identified during the present study might be expected to occur naturally in the excreta of many animals. Catechol and hippurate have long been known to be natural excretion products, but hexahydrohippurate also has been detected in the urine of cattle (Suemitsu et al., 1971). The microbial conversion of dietary shikimate into cyclohexanecarboxylate followed by conjugation with glycine in animal tissues appears to offer an explanation for this observation. This mechanism is an alternative to the suggestion that hexahydrohippurate may arise from microbial reduction of benzoate or hippurate (Rho \& Evans, 1975). However, more recently, Balba \& Evans (1977), by using a cow with rumen fistula, have demonstrated the conversion of shikimate into urinary hexahydrohippurate, thus confirming our results. As yet, none of the other metabolites identified is known to occur naturally in animal excreta, although their presence is confidently predicted.

\section{References}

Adamson, R. H., Bridges, J. W., Evans, H. E. \& Williams, R. T. (1970) Biochem. J. 116, 437-443

Asatoor, A. M. (1965) Biochim. Biophys. Acta 100, 290-292

Balba, M. \& Evans, W. C. (1977) Biochem. Soc. Trans. 5, 300-302 
Bohm, B. A. (1965) Chem. Rev. 65, 435-466

Booth, A. N., Robbins, D. J., Masri, M. S. \& DeEds, F. (1960) Nature (London) 187, 691

Brewster, D., Jones, R. S. \& Parke, D. V. (1976) Biochem. Soc. Trans. 4, 518-521

Brewster, D., Jones, R. S. \& Parke, D. V. (1977a) Xenobiotica 7, 109

Brewster, D., Jones, R. S. \& Parke, D. V. (1977b) Biochem. J. 164, 595-600

Brewster, D., Jones, R. S. \& Parke, D. V. (1977c) Xenobiotica 7, 601-609

Budzikiewicz, H., Djerassi, C. \& Williams, D. H. (1967) Mass Spectrometry of Organic Compounds, pp. 479-483, Holden-Day, San Francisco

Cotran, R., Kendrick, M. I. \& Kass, E. H. (1960) Proc. Soc. Exp. Biol. Med. 104, 424-426

Dacre, J. C. \& Williams, R. T. (1968)J. Pharm. Pharmacol. 20, 610-618

Evans, I. A. (1976) Bot. J. Linn. Soc. 73, 105-112

Evans, I. A. \& Osman, M. A. (1974) Nature (London) 250, 348-349
Haslam, E. (1974) The Shikimate Pathway, Butterworths, London

Indahl, S. R. \& Scheline, R. R. (1973) Xenobiotica 3, 549-556

IUPAC Rules (1970) J. Org. Chem. 35, 2849-2867

Lugg, J. H. W. \& Overall, B. T. (1948) Aust. J. Sci. Res. 1, 98-106

Metzenberg, R. L. \& Mitchell, H. K. (1954) J. Am. Chem. Soc. 76, 4187

Rho, E. M. \& Evans, W. C. (1975) Biochem. J. 148, 11-15

Rix, M. J., Webster, B. R. \& Wright, I. C. (1969) Chem. Ind. (London) 452

Scheline, R. R. (1966) J. Pharm. Pharmacol. 18, 664-669

Stavric, B. \& Stoltz, D. R. (1976) Food Cosmet. Toxicol. 14, 141-145

Suemitsu, R., Fujita, S. \& Kamata, T. (1971) Agric. Biol. Chem. 35, No. 1, 132-133

Whiting, G. C. \& Coggins, R. A. (1971) Antonie van Leeuwenhoek 37, 33-49

Whiting, G. C. \& Coggins, R. A. (1974) Biochem. J. 141, 35-42

Wood, P., English, J., Chakraborty, J. \& Hinton, R. (1975) Lab. Pract. 24, 739-740 